\title{
Experimental Investigation of Moment Curvature Characteristics of Ferrrocement Hollow Slab
}

\author{
Raj kishor sah ${ }^{1}$, M. Pradeep kumar ${ }^{2}$ \\ (Department of Civil Engineering, PSNA College of Engineering and Technology,Kothandaraman Nagar, \\ Dindigul -624 622, Tamilnadu, India)
}

\begin{abstract}
It is evident from literature review that in the recent decades the thrust for finding an alternative to the costly construction material is increasing several alternative have been tested across the globe. Some viable alternative are found, also many techniques of replacing the cement and addition of ferrocement is studied. The methods which are found to be cost effective and feasible are also tried in construction in various areas. Once such alternative technique is providing subsidiary cement in the way of addition of ferrocement in hollow slab. In this paper, the general behaviour of Fiber Reinforced Ferrocement composite and the studies carried out by various investigators on mechanical properties are summarized and presented. In this experiment momentcurvature behaviour,Ductility, Stiffness degradation,Ultimate load carrying capacity and Energy absorption were determined. The comparision is of load carrying capacity, stiffness degradation, Ductility and Energy absorption of fiber reinforced Ferrocement Hollow Slab with the same slab without fiber. This paper details the attempt made to check moment-curvature characteristics of ferrocement hollow slab.
\end{abstract}

Keywords: HFFC,FRC,Ferrocement,Ductility,Stiffness degradation

\section{Introduction}

Slabs are the most widely used structural elements of modern structural complex and the reinforced concrete slab is the most useful discovery for supporting lateral loads in buildings. In addition to the supporting lateral loads, slabs act as deep horizontal girders to resist wind and earthquake forces that act on a multistoried frame. Their action as girder diaphragms of great stiffness is important in restricting the lateral deformations of a multistoried frame.

The cast in - situ reinforced concrete roof floor slab is the simplest form of slab construction, but it is rather wasteful in materials particularly cement. Substantial savings can be effected by modifying the composition of the slab so that its weight is reduced without imparing its strength or behaviour. For that we go for ferrocement slabs. Ferrocement is a composite material which is made up of cement mortar reinforced with steel fibers in the form of wire mesh, in which the brittle cement mortar matrix is reinforced with layers of ductile wire meshes dispersed throughout, thus resulting in a material of better structural performance.

While the mortar provides the mass, the steel fiber imparts tensile strength and deformability to the material. Ferrocement is a type of thin wall reinforced concrete commonly constructed of hydraulic cement mortar reinforced with closely spaced layers of continuous and relatively small size wire mesh. In its role as a thin reinforced concrete product and as laminated cement - based composite, ferrocement has found itself in numerous applications both in new structures and repair and rehabilitation of existing structures. Compared with the conventional reinforced concrete, ferrocement is reinforced in two directions; therefore, it has homogenous isotropic properties in two directions. Benefiting from its usually high reinforcement ratio, ferrocement generally has a high tensile strength and a high modulus of rupture. In addition, because the specific surface of reinforcement of ferrocement is one to two orders of magnitude higher then that of reinforced concrete, larger bond forces develop with matrix resulting in average crack spacing and width more than one order of magnitude smaller than in conventional reinforcement concrete. Other appealing features of ferrocement include ease of prefabrication and low cost in maintenance and repair. Based on the aforementioned advantages, the typical applications of ferrocement include water tanks, boats, housing wall panel, roof, formwork and sunscreen.

As a laminated composite, ferrocement often suffers from severe spalling of matrix cover and delamination of extreme tensile layer at high reinforcement ratio, resulting in premature failure. Therefore, serviceability consideration rather than strength limit would dominate composite design. Adding discontinuous short fiber to cementitious matrix, which could bring significant improvement in ductility and shear capacity as well as moderate increase in tensile strength, turns out to be a logical solution to solve or alleviate these problems. Also for a good earthquake resistant design is to have sufficient ductile materials at points of tensile stresses. 


\section{Scope And Objective}

So far moment - curvature relationship for reinforced concrete slabs, beams and ferrocement beams has been developed. In this thesis, moment - curvature behaviour, Ductility, Stiffness degradation, Ultimate load carrying capacity and Energy absorption were determined. These parameters have an important role to play in predicting the behaviour of ferrocement members under flexure. The main objective of this thesis is

* To determine the Moment - Curvature Characteristics of the Fiber Reinforced Ferrocement Hollow Slab under cyclic loading.

- To compare the parameters of load carrying capacity, stiffness degradation, Ductility and Energy absorption of fiber reinforced Ferrocement Hollow Slab with the same slab without fiber.

\section{Literature Review}

\subsection{General}

In this chapter, the general behaviour of Fiber Reinforced Ferrocement composite and the studies carried out by various investigators on mechanical properties are summarized and presented.

\subsubsection{Review of Literature}

1. K.Ramesh, D.R.Seshu, have derived the characteristic equation of the stress - strain curve for Hybrid Ferro Fiber Concrete which was used to study the moment - curvature characteristics of HFFC sections. The theoretical procedure has been validated by conducting an experimental investigation on 23 reinforced concrete beams provided with HFFC at critical sections. The correlation between experimental and analytical values of ultimate moments and corresponding curvatures arrived at based on the above procedure is found to be good. The moment - curvature diagram of HFFC sections can be idealized as a bi - linear form.

2. P.J. Walker summarizes the experimental and theoretical work undertaken to study the behaviour of ferrocement elements in flexure. Results of six beam test are presented. The influences of both mesh content and cement mortar properties on beam behavior are considered. Measurements ndicated that increased mesh content and mortar strength enhanced both the ultimate moment capacity and stiffness of the beams.

3. M.S.Mathews, J.Sudhakumar and PJayasree have investigated the durability aspects of ferrocement in marine environment by conducting laboratory accelerated tests and field tests. The results have indicated that the ferrocement specimens subjected to accelerated tests and those in the splash zone of field tests suffered appreciable loss of strength. The specimens in the atmospheric and immersion zone showed improvements in the ultimate tensile strength during the test.

\section{Specimen Details}

Two slab panels of size $3000 \mathrm{~mm}$ in length and $140 \mathrm{~mm}$ in depth with the breadth of $770 \mathrm{~mm}$ in the bottom and $690 \mathrm{~mm}$ in the top were cast. The details of the specimen are mentioned in table 3.2

\begin{tabular}{|l|l|}
\hline Main Rods & $8 \mathrm{~mm} \Phi @ 130 \mathrm{~mm}$ spacing \\
\hline Distributor Rods & $4 \mathrm{~mm} \Phi @ 150 \mathrm{~mm}$ spacing \\
\hline Shear Connectors & 4mm $\Phi @ 150 \mathrm{~mm}$ spacing \\
\hline Chicken Mesh & 3layers in both flanges \\
\hline Clear Cover & $5 \mathrm{~mm}$ \\
\hline
\end{tabular}

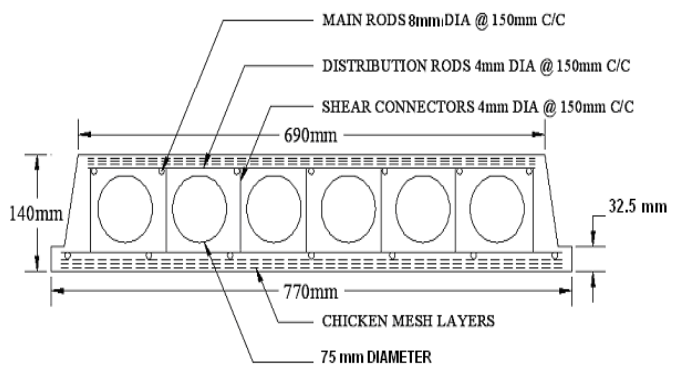

fig : cross section of the specimen 


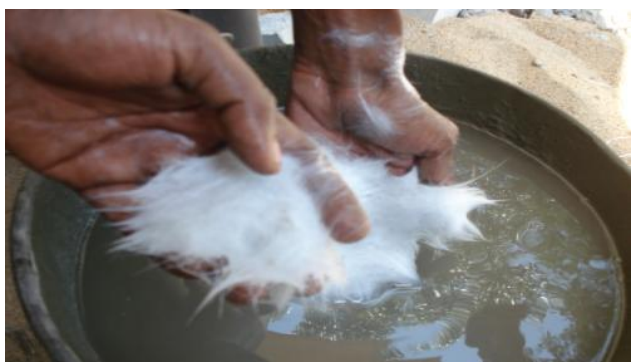

RECRON

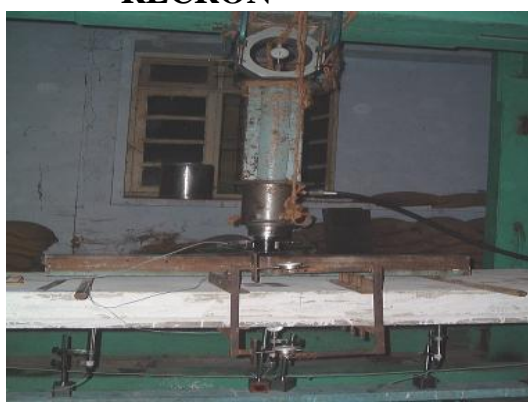

EXPERIMENTAL SETUP

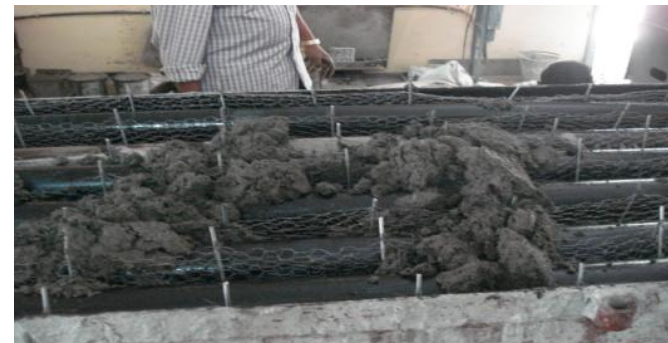

CASTING

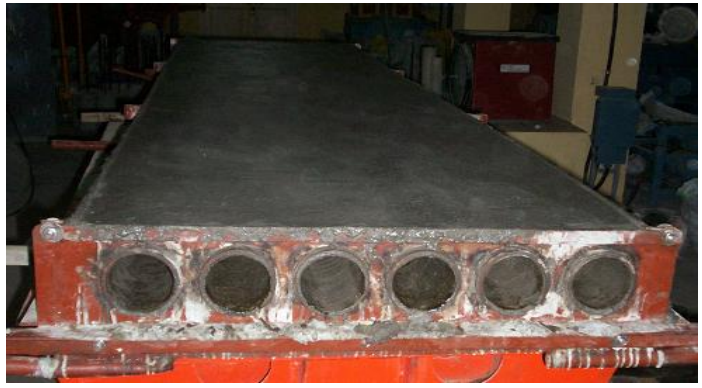

FINISHED SLAB

V.

Test Procedure

To determine the Moment - Curvature characteristics and the Ultimate load carrying capacity of the Fiber Reinforced Ferrocement Hollow Slab, a total number of four slabs were cast. The effective span of the slab was $2800 \mathrm{~mm}$. The Fiber Reinforced Ferrocement Hollow Slab was tested in a 25 tones Self Straining loading frame with $500 \mathrm{kN}$ capacity proving ring. The specimen is placed on the Self Straining load frame with its one end hinged and other end as roller. The load applied to the slab was cyclic loading with an increment of $5 \mathrm{kN}$ load in each cycle by means of hydraulic jack. The load was applied till the slab reaches its ultimate load. The top and bottom strains of the Fiber Reinforced Ferrocement Hollow Slab are measured by means of curvature meter. The crack patterns are also observed.

The history of the load sequence followed for the test is presented in graph 3.1. Totally 11 cycles were imposed.

\section{Test result of component specimen}

With recron $3 \mathrm{~s}$ fiber

Compressive strength of cube $-37.63 \mathrm{Mpa}$

Compressive strength of cylinder $-32.45 \mathrm{Mpa}$

Without recron 3 s fiber

Compressive strength of cube $-31 \mathrm{Mpa}$

Compressive strength of cylinder $-30.56 \mathrm{Mpa}$
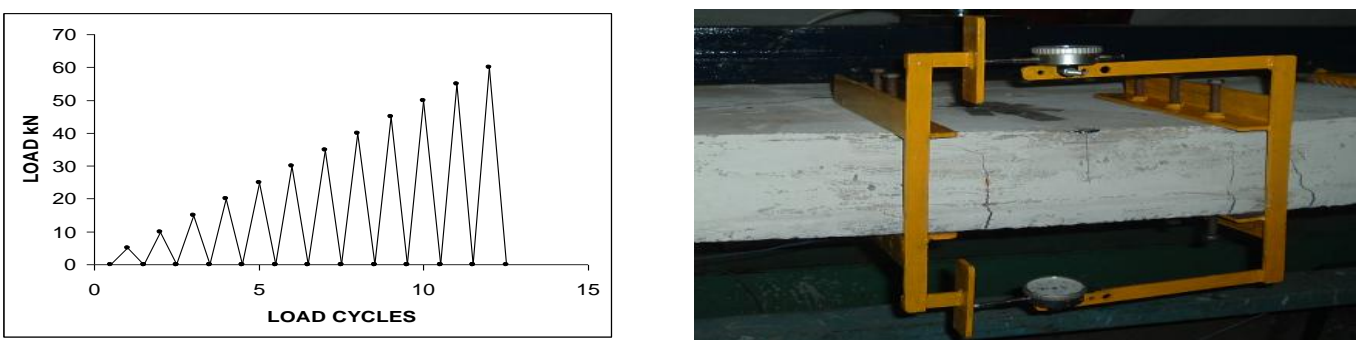

GRAPH LOAD SEQUENCE DIAGRAM

FIG.CURVATURE METER

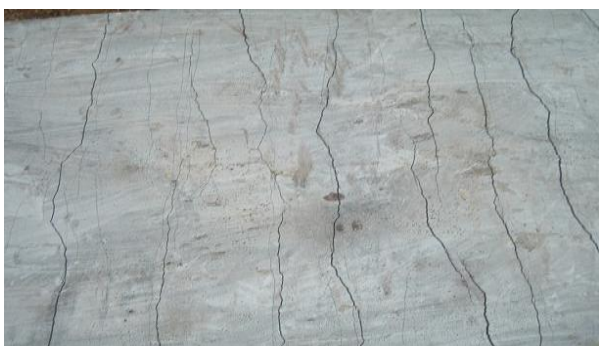

FIG CRACK PATTERN

www.iosrjournals.org 
Experimental Investigation Of Moment Curvature Characteristics Of Ferrrocement Hollow Slab Behaviour of Ferrocement Hollow Slab without Fiber

Table 5.1 Experimental results of the slab without Recron fiber

\begin{tabular}{|c|c|c|c|c|c|c|c|}
\hline \multirow{2}{*}{$\begin{array}{l}\text { Load } \\
\text { cycle } \\
\text { No. }\end{array}$} & \multirow[t]{2}{*}{$\begin{array}{l}\text { Moment } \\
\text { kN m }\end{array}$} & \multirow{2}{*}{$\begin{array}{l}\text { Curvature } \\
\mathbf{m m}^{-1} \\
\times \mathbf{1 0}^{-2}\end{array}$} & \multicolumn{2}{|c|}{ Ductility factor } & \multirow{2}{*}{$\begin{array}{l}\text { Stiffness } \\
\text { degradation } \\
\mathrm{kN} \mathrm{m}^{2}\end{array}$} & \multicolumn{2}{|c|}{$\begin{array}{l}\text { Energy absorption } \\
\text { kN }\end{array}$} \\
\hline & & & Relative & Cumulative & & Relative & Cumulative \\
\hline 1 & 2.3 & .035 & $\begin{array}{l}0.0959 \\
\end{array}$ & $\begin{array}{l}0.0959 \\
\end{array}$ & 16.67 & 0.268 & 0.268 \\
\hline 2 & 4.7 & 0.07 & 0.1808 & 0.2767 & 12 & 0.6062 & 0.8742 \\
\hline 3 & 7 & 0.105 & 0.271 & 0.5477 & 8.8 & 0.775 & 1.649 \\
\hline 4 & 9.3 & 0.126 & 0.328 & 0.8757 & 8.3 & 1.175 & 2.824 \\
\hline 5 & 11.7 & 0.202 & 0.523 & 1.3987 & 6.67 & 5.625 & 8.449 \\
\hline 6 & 14 & 0.337 & 1.027 & 2.426 & 5 & 20.125 & 28.574 \\
\hline 7 & 16.3 & 0.53 & 1.452 & 3.878 & 4.5 & 21.125 & 28.574 \\
\hline 8 & 18.7 & 0.837 & 2.293 & 6.171 & 3 & 39.125 & 88.824 \\
\hline 9 & 21 & 1.102 & 3.019 & 9.190 & 2.5 & 53.375 & 142.199 \\
\hline 10 & 23.3 & 1.492 & 4.087 & 13.277 & 2.4 & 81.75 & 223.949 \\
\hline 11 & 24.7 & 2.58 & 6.712 & 19.989 & 2.1 & 196.37 & 420.319 \\
\hline
\end{tabular}

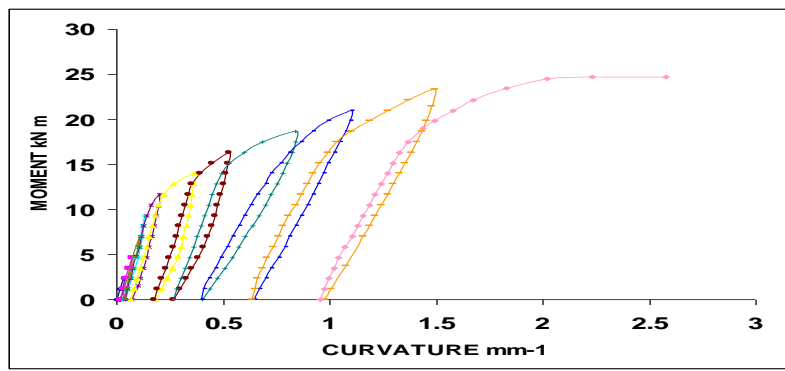

GRAPH 5.1.1.a MOMENT Vs CURVATURE

Behaviour Of Fiber Reinforced Ferrocement Hollow Slab

\begin{tabular}{|c|c|c|c|c|c|c|c|}
\hline \multirow{2}{*}{$\begin{array}{l}\text { Load } \\
\text { cycle } \\
\text { No. }\end{array}$} & \multirow[t]{2}{*}{$\begin{array}{l}\text { Moment } \\
\text { kN m }\end{array}$} & \multirow{2}{*}{$\begin{array}{l}\text { Curvature } \\
\mathbf{m m}^{-1} \\
\mathbf{x} \mathbf{1 0}^{-2}\end{array}$} & \multicolumn{2}{|c|}{ Ductility factor } & \multirow{2}{*}{$\begin{array}{l}\text { Stiffness } \\
\text { degradation } \\
\mathrm{kN} \mathrm{m}^{2}\end{array}$} & \multicolumn{2}{|c|}{$\begin{array}{l}\text { Energy absorption } \\
\text { kN }\end{array}$} \\
\hline & & & Relative & Cumulative & & Relative & Cumulative \\
\hline 1 & 2.3 & 0.043 & 0.1102 & 0.1102 & 19 & 0.1156 & 0.1156 \\
\hline 2 & 4.7 & 0.071 & 0.182 & 0.292 & 15 & 0.1937 & 0.3093 \\
\hline 3 & 7 & 0.107 & 0.274 & 0.5662 & 13 & 0.925 & 1.234 \\
\hline 4 & 9.3 & 0.133 & 0.331 & 0.8972 & 11.25 & 2.75 & 3.984 \\
\hline 5 & 11.7 & 0.21 & 0.5487 & 1.4459 & 10 & 4.85 & 8.834 \\
\hline 6 & 14 & 0.436 & 1.1179 & 2.5638 & 10 & 22.125 & 30.959 \\
\hline 7 & 16.3 & 0.857 & 2.197 & 4.7608 & 7 & 46.37 & 77.33 \\
\hline 8 & 18.7 & 1.093 & 2.795 & 7.556 & 5.2 & 26 & 103.33 \\
\hline 9 & 21 & 1.314 & 3.369 & 10.925 & 3.6 & 21 & 124.33 \\
\hline 10 & 23.3 & 1.607 & 4.1205 & 15.0453 & 3 & 44.25 & 168.58 \\
\hline 11 & 28 & 2.857 & 7.371 & 22.416 & 2.67 & 347 & 519.58 \\
\hline
\end{tabular}

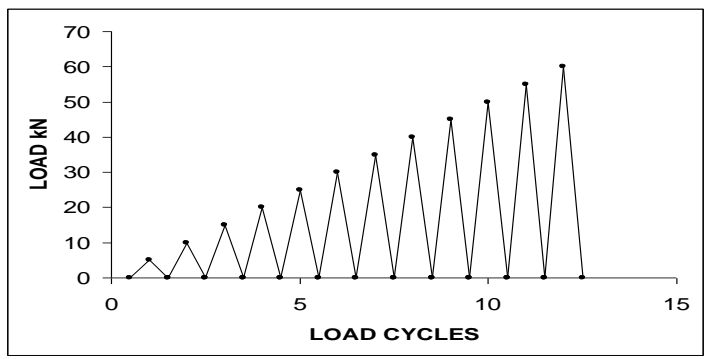

Graph 5.1.1.b Load Sequence Diagram 


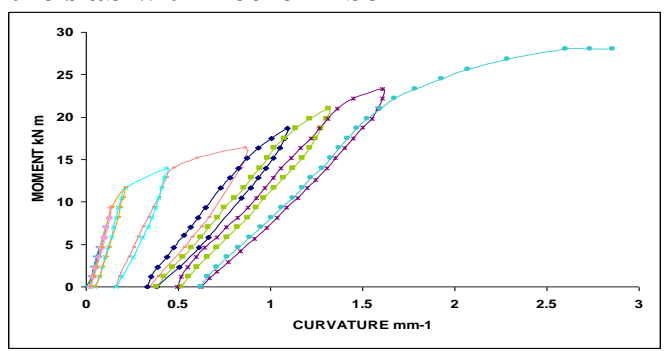

GRAPH5.1.2 MOMENTVSCURVATURE

\section{Conclusion}

The first crack load has been observed that the fiber reinforced ferrocement hollow slab was more than that of ferrocement hollow slab without fiber.

$>$ The ultimate moment carrying capacity is marginally increased for the fiber reinforced ferrocement hollow slab than the ferrocement hollow slab without fiber.

$>$ In general there is stiffness degradation for both the slabs.

$>$ Initial stiffness of the ferrocement hollow slab without fiber is lower than that of the fiber reinforced ferrocement hollow slab.

$>$ The cumulative curvature ductility for fiber reinforced ferrocement hollow slab is 1.121 times more than that of ferrocement hollow slab without fiber.

$>$ The Energy absorption for the fiber reinforced ferrocement hollow slab is 1.24 times greater than that of the ferrocement hollow slab without fiber.

$>$ By the inclusion of the fiber, the failure pattern of the slab is changing considerably i.e.,

$>$ The crack width is reduced in case of fiber reinforced ferrocement hollow slab.

$>$ The ductility and energy absorption is relatively increased in the fiber reinforced ferrocement hollow slab.

$>$ Since the fiber reinforced ferrocement hollow slabs have high ductility they have the ability to resist earthquake and they can be used for buildings constructed in the earthquake zone.

\section{Acknowledgements}

This research could not have been complete without Dr. N. Mahendran who not only served as my supervisor but also encourage me throughtout my academic program. He and the other faculty members Dr. Gopala Krishan guided me thorough the isserlation process,never accepting less than mybest efforts. I thank them all. I also wish to express my sincere thanks to the Chennai Civil-Tech Research pvt. Ltd. for the guidance in my research.

I gratefully acknowledge the PSNA College of Engineering and Technology, Dindigul for extending all fascilites and words of encouragement from the principal while working on this research.

\section{References}

[1] K.Ramesh, D.R.Seshu, "Moment Curvature Characteristics of Hybrid Ferro Fiber Concrete (HFFC) Beam" Journal of Ferrocement, Vol.33, No.1, Jan 2003, pp. 15-28.

[2] M.S.Mathews, J.Sudhakumar and PJayasree "Durability Studies On Ferrocement” Journal of Ferrocement, Vol.23, No.1, Jan 1991

[3] P.Balaguru, "Prediction of Crack Width in Ferrocement Beams" Journal of Ferrocement, Vol. 11, No.3, July 1981, pp. $203-213$.

[4] P.J. Walker "Moment - Curvature Relations for Ferrocement Beams" Journal of Ferrocement, Vol. 25, No. 4, Oct. 1995, pp. 347359.

[5] A.Kumar "Ferrocement Box Sections-viable option for floors and roof of multi-storeyed buildings" Asian Journal of civil Engineering (Building and Housing), Vol. 6, No. 6, 2005, pp. 569-582.

[6] W.N.Al Rifaie and A.H.K.Al Shukur "Effect of Wetting Drying Cycles in Fresh Water on the Flexural Strength of Ferrocement" Journal of Ferrocement, Vol. 31, No.2, July 1995. 